\title{
Correction to: American Society for Enhanced Recovery (ASER) and Perioperative Quality Initiative (POQI) joint consensus statement on perioperative fluid management within an enhanced recovery pathway for colorectal surgery
}

Robert H. Thiele ${ }^{1}$, Karthik Raghunathan ${ }^{2}$, C. S. Brudney ${ }^{3}$, Dileep N. Lobo ${ }^{4}$, Daniel Martin ${ }^{5,6}$, Anthony Senagore? Maxime Cannesson ${ }^{8}$, Tong Joo Gan ${ }^{9}$, Michael Monty G. Mythen ${ }^{10}$, Andrew D. Shaw ${ }^{11}$, Timothy E. Miller ${ }^{12^{*}}$ and For the Perioperative Quality Initiative (POQI) I Workgroup

\section{Correction}

After publication of this article (Thiele et al., 2016), it was noticed that the HTML version contained errors with the collaborator group, the Perioperative Quality Initiative (POQI) I Workgroup, preventing the group members from being searchable within indexing repositories. The corrected declarations section can be found here.

\footnotetext{
Acknowledgements

POQI I conference directors (named authors on all manuscripts).

- Timothy E Miller, Department of Anesthesiology, Duke University Medical Center, NC, USA

- Andrew D Shaw, Department of Anesthesiology, Vanderbilt University Medical Center, Nashville, TN, USA.

- Michael G Mythen, Department of Anaesthesia, University College London, London, UK.

- Tong J Gan, Department of Anesthesiology, Stony Brook University School of Medicine, NY, USA.

Group A - analgesia.

- Matthew D. McEvoy, Department of Anesthesiology, Vanderbilt University Medical Center, Nashville, TN, USA (chair).

- Michael J. Scott, Department of Anaesthesia, Royal Surrey County NHS Foundation Hospital, Surrey, UK (co-chair).

- Deborah Gordon, RN, Department of Anesthesiology and Pain Medicine, University of Washington.

- Stuart Grant, Department of Anesthesiology, Duke University Medical Center, NC, USA

- Julie K.M. Thacker, Division of Advanced Oncologic and GI Surgery, Duke University Medical Center, NC, USA.
}

\footnotetext{
*Correspondence: timothy.miller2@duke.edu

${ }^{12}$ Division of General, Vascular and Transplant Anesthesia, American Society for Enhanced Recovery, Duke University Medical Center, Durham, NC 27710, USA

Full list of author information is available at the end of the article
}

- Christopher L. Wu, Department of Anesthesiology, The Johns Hopkins University School of Medicine, MD, USA.

Group B - fluids.

- Robert H. Thiele, Departments of Anesthesiology and Biomedical Engineering, University of Virginia School of Medicine, VA, USA (chair). - Karthik Raghunathan, Department of Anesthesiology, Duke University Medical Center, USA (co-chair).

- CS Brudney, Department of Anesthesiology, Duke University Medical Center, USA.

- Dileep N Lobo, Division of Gastrointestinal Surgery, Nottingham University Hospitals and University of Nottingham, Nottingham, UK.

- Dr. Daniel Martin, Royal free Perioperative Research Group, Royal Free Hospital, London, UK.

- Anthony Senagore, Department of Surgery, University of Texas-Medical Branch at Galveston, Galveston, TX, USA.

Group C - infection.

- Stefan D Holubar, Department of Surgery, Dartmouth-Hitchcock Medical

Center, NH, USA (chair).

- Traci Hedrick, Department of Surgery, University of Virginia School of Medicine, VA, USA (co-chair).

- John Kellum, Department of Critical Care Medicine, University of Pittsburgh School of Medicine, Pittsburgh, PA, USA.

- Ruchir Gupta, Department of Anesthesiology, Stony Brook University School of Medicine, NY, USA.

- Mark Hamilton, Department of Anaesthesia, St. George's Hospital and Medical School, London, UK.

Group D - outcomes.

-S. Ramani Moonesinghe, Department of Anaesthesia, University College

London, London, UK. (chair).

- Mike PW Grocott, Department of Anesthesia and Critical Care Medicine,

University of Southampton, UK (co-chair).

- Elliott Bennett-Guerrero, Department of Anesthesiology, Stony Brook University School of Medicine, NY, USA.

- Thomas J Hopkins, Department of Anesthesiology, Duke University Medical Center, NC, USA.

- Roberto Bergamaschi, Department of Surgery, Stony Brook University School of Medicine, NY, USA.

- Stuart McCluskey, Department of Anesthesia, University of Toronto, ON, Canada. 


\section{Author details}

'Departments of Anesthesiology and Biomedical Engineering, Divisions of Cardiac, Thoracic, and Critical Care Anesthesiology, UVA Enhanced Recovery after Surgery (ERAS) Program, University of Virginia School of Medicine,

Charlottesville, VA, USA. ${ }^{2}$ Department of Anesthesiology, Duke University Medical Center, Durham, NC 27710, USA. ${ }^{3}$ Duke University and Durham VA Medical Center, Durham, NC, USA. ${ }^{4}$ Gastrointestinal Surgery, National Institute for Health Research Nottingham Digestive Diseases Biomedical Research Unit, Nottingham University Hospitals and University of Nottingham, Queen's Medical Centre, Nottingham NG7 2UH, UK. ${ }^{5}$ Division of Surgery and Interventional Science, University College London, Royal Free Hospital, London NW3 2QG, UK. ${ }^{6}$ Anaesthetic Department, Royal Free Perioperative Research Group, Royal Free Hospital, London NW3 2QG, UK. 'Department of Surgery, University of Texas-Medical Branch at Galveston, Galveston, TX 77555, USA. ${ }^{8}$ Department of Anesthesiology and Perioperative Medicine, University of California Los Angeles, Los Angeles, CA, USA. ${ }^{9}$ Department of Anesthesiology, Stony Brook University School of Medicine, Stony Brook, NY, USA. ${ }^{10}$ University College London Hospitals, National Institute of Health Research Biomedical Research Centre, London, UK. ${ }^{11}$ Department of Anesthesiology, Vanderbilt University School of Medicine, Nashville, TN, USA. ${ }^{12}$ Division of General, Vascular and Transplant Anesthesia, American Society for Enhanced Recovery, Duke University Medical Center, Durham, NC 27710 USA.

Received: 22 February 2018 Accepted: 23 February 2018

\section{Published online: 10 April 2018}

\section{Reference}

Thiele RH, Raghunathan K, Brudney CS, Lobo DN, Martin D, Senagore A, et al. American Society for Enhanced Recovery (ASER) and Perioperative Quality Initiative (POQI) joint consensus statement on perioperative fluid management within an enhanced recovery pathway for colorectal surgery. Perioperative Medicine. 2016;5:24. https://doi.org/10.1186/s13741-016-0049-9 